\title{
Saúde Penitenciária, Promoção de Saúde e Redução de Danos do Encarceramento: Desafios para a Prática do Psicólogo no Sistema Prisional
}

\author{
Lucas Gonzaga do Nascimento ${ }^{1}$ \\ ${ }^{1}$ Universidade do Estado do Rio de Janeiro, RJ, Brasil.
}

\author{
Maria Márcia Badaró Bandeira ${ }^{1}$ \\ ${ }^{1}$ Universidade do Estado do Rio de Janeiro, RJ, Brasil.
}

\begin{abstract}
Resumo: Este trabalho visa discutir o papel do psicólogo na garantia do direito à saúde no âmbito do sistema prisional. O trabalho do psicólogo em prisões ainda se encontra atrelado à realização dos exames criminológicos, que afasta grande parte dos profissionais de atuações mais inventivas e voltadas à garantia de direitos. Por meio de pesquisa bibliográfica, indicaremos alguns dos principais desafios no campo da saúde penitenciária, que, nas recentes pesquisas qualitativas, apontam também para a percepção dos problemas e as estratégias no enfrentamento às graves condições de insalubridade. Consideramos que a Psicologia pode contribuir para a intersetorialidade entre os campos da execução penal e do direito à saúde. Ainda que a questão da saúde penitenciária seja enormemente prejudicada pelo superencarceramento e pelas péssimas condições do sistema prisional brasileiro, os profissionais da Psicologia - aliados aos demais técnicos e funcionários do sistema penal - podem ter um importante papel para a redução dos danos dos efeitos do encarceramento, desde que sua prática seja contextualizada e comprometida com a garantia dos direitos humanos.
\end{abstract}

Palavras-chave: Psicologia Jurídica, Sistema Prisional, Saúde Penitenciária, Promoção de Saúde, Direitos Humanos.

\section{Penitentiary Health, Health Promotion and Harm Reduction of Imprisonment: Challenges to the Psychologist's Practice in the Prison System}

\begin{abstract}
This work aims at discussing the psychologist's role in the guarantee of the right to health in the ambit of the prison system. The psychologist's work in prisons is still linked to making criminological examinations, what makes a big part of professionals be apart from a more inventive acting, dedicated to the guarantee of rights. Through bibliographical research, we will indicate some of the principal challenges in the field of penitentiary health, that, in recent qualitative researches, also point out to the perception of the problems and the strategies in the confrontation with seriously insalubrious conditions. We consider that psychology can contribute to the intersectoriality between the fields of the penal execution and the right to health. Even though the matter of penitentiary health is enormously damaged by mass incarceration and by the terrible conditions of the Brazilian prison system, psychologists - united with the other technicians and agents of the criminal justice system - can play an important role in the reduction of the damages of the effects of imprisonment, but only if their practice is contextualized and committed to the guarantee of human rights.
\end{abstract}

Keywords: Juridical Psychology, Prison System, Penitentiary Health, Health Promotion, Human Rights, 


\title{
Salud Penitenciaria, Promoción de Salud y Reducción de Daños del Encarcelamiento: Desafíos para la Práctica del Psicólogo en el Sistema Penitenciario
}

\begin{abstract}
Resumen: Este trabajo pretende discutir el papel del psicólogo en la garantía del derecho a la salud en el ámbito del sistema penitenciario. El trabajo del psicólogo en prisiones aún se encuentra atado a la realización de los exámenes criminológicos, que aleja gran parte de los profesionales de actuaciones más inventivas y enfocadas a la garantía de derechos. Por medio de investigación bibliográfica, indicaremos algunos de los principales desafíos en el campo de la salud penitenciaria, que en las recientes investigaciones cualitativas apuntan también a la percepción de los problemas y las estrategias en el enfrentamiento a las graves condiciones de insalubridad. Consideramos que la psicología puede contribuir a la intersectorialidad entre los campos de la ejecución penal y del derecho a la salud. Aunque la cuestión de la salud penitenciaria sea enormemente perjudicada por el superencarcelamiento y por las pésimas condiciones del sistema penitenciario brasileño, los profesionales de la psicología, aliados a los demás técnicos y funcionarios del sistema penal, pueden tener un importante papel para la reducción de los daños de los efectos del encarcelamiento, siempre que su práctica sea contextualizada y comprometida con la garantía de los derechos humanos.
\end{abstract}

Palabras clave: Psicología Jurídica, Sistema Penitenciario, Salud Penitenciaria, Promoción de Salud, Derechos Humanos.

\section{Introdução}

Na literatura sobre a prática do psicólogo no sistema prisional, diversas questões ético-políticas são abordadas, sendo uma das principais a tensão existente entre uma atuação voltada majoritariamente para a confecção de avaliações por meio dos exames criminológicos e uma outra que busca se consolidar enquanto promotora de direitos, saúde e bem-estar no ambiente prisional (Bandeira, 2003; 2012; Bandeira, Camuri, \& Nascimento, 2011; Barros, \& Amaral, 2016; Bocco, 2013; Carvalho, 2011; Hoffman, 2012; Karam, 2011; Kolker, 2011; Rauter, 2007; 2010; 2016; Rossotti, \& Bicalho, 2012).

Segundo a Lei de Execução Penal - LEP (Lei No 7.210, 1984), a Psicologia estaria inserida no sistema prisional para concretizar o Princípio da Individualização das Penas, fazendo parte da equipe técnica que compõe as Comissões Técnicas de Classificação (CTC) e os Centros de Observação Criminológica (COC), junto a outros profissionais, como assistentes sociais, psiquiatras e chefes da segurança. Segundo este princípio, cada pessoa sentenciada deveria cumprir a sua pena de acordo com um "tratamento penal" individualizado com vistas a ser "reeducado" e "ressocializado", de modo que, ao término de sua pena pudesse estar em condições de viver em sociedade sem cometer novos delitos. Entretanto, como destacam Bandeira, Almeida e Santos (2014), ao observarmos a noção do referido "tratamento penal" na Exposição de Motivos da LEP, identificamos que não há a conotação do cuidado, mas sim de práticas como "aconselhar", "orientar", "educar" e "disciplinar", expressões também comuns em outros espaços de trabalho, como escolas, hospitais psiquiátricos, empresas, dentre outros, chamadas por Foucault (2014) de práticas de "ortopedia social".

A princípio, os profissionais da Psicologia deveriam realizar avaliações psicológicas no momento do começo do cumprimento da pena de liberdade e, posteriormente, realizar seu acompanhamento, propondo atividades e inserção em programas educativos, laborais e de saúde, realizando também novas avaliações para subsidiar decisões judiciais no momento de progressão de regime ou livramento condicional. Tais avaliações dizem respeito ao exame criminológico, por meio do qual se espera que o psicólogo avalie a personalidade e os efeitos do "tratamento penal" sobre a subjetividade dos indivíduos, de modo a aferir se voltarão a cometer crimes ou não. Ao longo deste trabalho, para facilitar a leitura, utili- 
zaremos a sigla PPL para nos referirmos às pessoas privadas de liberdade.

Em 2003 foi promulgada a Lei ${ }^{\circ} 10.792$, que altera o artigo 112 da LEP, eliminando a necessidade dos exames criminológicos para a progressão de regime e para o livramento condicional, permanecendo apenas os outros requisitos listados na LEP: cumprimento de ao menos um sexto da pena no regime anterior e ostentar bom comportamento carcerário, comprovado pelo diretor do estabelecimento, precedida de manifestação do Ministério Público e do defensor.

Esta mudança foi motivada pelo reconhecimento das possíveis falhas técnicas e do caráter irrefutável das conclusões do exame, o que fere o direito das PPL ao contraditório, como também viola sua intimidade, indo além dos fatos pertinentes ao processo desencadeado pelo suposto crime cometido. Tais alterações causaram insatisfações no âmbito do judiciário brasileiro, provocando o posicionamento dos Tribunais Superiores que decidiram pela opcionalidade dos exames, devendo ser solicitados apenas em casos específicos. Outra mudança ocorre no artigo $6^{\circ}$ da LEP, retirando a atribuição da CTC de acompanhamento da execução penal e deixando a cargo dessa Comissão apenas a realização do exame criminológico inicial. Nesse mesmo ano foi publicada a Portaria Interministerial $n^{\circ} 1.777 / 2003$ que institui o Plano Nacional de Saúde no Sistema Penitenciário (PNSSP), cujos princípios foram desenvolvidos a partir da lógica de atenção à saúde integral proveniente do Sistema Único de Saúde (SUS). O PNSSP diz, no item 6.1, que a equipe mínima de assistência à saúde em cada unidade prisional é composta por "médico, enfermeiro, dentista, psicólogo, assistente social, auxiliar de enfermagem e atendente de consultório dentário, com jornada de 20 horas semanais, para atenção de até 500 pessoas presas"(Portaria Interministerial № 1.777, 2003) .

Delineiam-se, dessa forma, novas possibilidades de atuação do psicólogo no sistema prisional, não mais restrito apenas à confecção de laudos e pareceres, mas atento às questões de ordem subjetiva e à assistência à saúde das PPL durante a execução penal. Com a esperada diminuição do número de exames criminológicos a serem realizados, os profissionais da Psicologia estariam liberados para desempenhar outras funções no cárcere. No entanto, na prática, um grande número de juízes continua a exigir dos técnicos que trabalham na execução penal a confecção dos exames criminológicos para a maior parte das PPL, desconsiderando as mudanças preconizadas pela Lei $\mathrm{n}^{\circ} 10.792 / 2003$. Isso acaba por afastar muitos psicólogos de uma atuação voltada para a assistência à saúde, implicando em delicadas questões éticas para a categoria dos psicólogos e também para os demais técnicos da execução penal, como os psiquiatras e assistentes sociais. Tais questões podem ser melhor compreendidas quando contextualizamos a prática psicológica no cenário nacional da execução penal e, de forma geral, do sistema de justiça criminal brasileiro.

O Brasil ocupa o $3^{\circ}$ lugar no ranking mundial de países com a maior população carcerária, possuindo cerca 726 mil PPL no censo divulgado em 2017 pelo sistema de informações penitenciárias (Brasil, 2017a), atrás apenas dos Estados Unidos (2.217.000) e da China (1.657.812). Do total de pessoas encarceradas no Brasil, cerca de $40 \%$ não foram formalmente condenadas, cumprindo prisões provisórias. Tendo em vista as condições insalubres e completamente inadequadas das prisões brasileiras, pode-se compreender os altos índices de mortalidade e a dificuldade de se implementar serviços de saúde que sejam eficazes nesse contexto. No Rio de Janeiro, por exemplo, a taxa de detecção de tuberculose é cerca de 30 vezes superior à população geral do estado (Sánchez, \& Larouzé, 2016).

Do total de pessoas condenadas e encarceradas no Brasil hoje, quase um terço (28\%) foi acusado de envolvimento com o tráfico de drogas. Este é o maior percentual de condenações por tipo de crimes, seguido de roubo (25\%), furto (13\%), homicídio (10\%), dentre outros. Pode-se dizer, a partir destes números, que a maior parte da população carcerária brasileira não foi condenada por crimes que atentam diretamente contra a vida, e não necessariamente envolvem o uso de violência. A acusação de crime de tráfico de drogas segue aumentando largamente as cifras do sistema penal brasileiro, o que é impulsionado pela política de drogas repressiva e seu modelo de enfrentamento bélico correspondente, baseado no modelo norte-americano de "guerra às drogas". Dessa forma, em nome da "luta contra o tráfico", são autorizadas diversas formas de desrespeito aos direitos humanos. As Unidades de Polícia Pacificadoras (UPP) são, no Rio de Janeiro, um dos sinais mais visíveis do fracasso da política de enfrentamento bélico ao tráfico de drogas, transformando as áreas mais empobrecidas em verdadeiros campos de guerra por meio da gestão milita- 
rizada do cotidiano das comunidades, evidenciando verdadeiras políticas de extermínio das populações periféricas criminalizadas (D'Elia Filho, 2015).

Apesar da pena de morte ter sido abolida do ordenamento jurídico brasileiro, as políticas de segurança pública e de execução penal produzem mortes rotineiramente. No Rio de Janeiro, dados do Instituto de Segurança Pública (ISP) informam que, apenas no ano de 2017, as polícias civil e militar do estado foram responsáveis por 1.124 homicídios decorrentes de intervenção policial (Anistia Internacional, 2018). No campo da execução penal, levantamentos feitos por dois conhecidos noticiários brasileiros mostram uma realidade aterradora. Entre 2014 e 2017, 6.368 pessoas morreram sob a custódia do Estado, seja por doenças, homicídios ou suicídios, alcançando uma média maior que quatro pessoas mortas por dia (Mello, \& Castro, 2018). Apenas no sistema prisional do Rio de Janeiro, entre janeiro de 2015 e agosto de 2018, 517 pessoas morreram em decorrência de doenças, enquanto que, no mesmo período, 37 pessoas foram assassinadas, um número 14 vezes menor (Costa, \& Bianchi, 2017). Segundo dados do Infopen (Brasil, 2017a), a taxa de óbitos por motivos de saúde no sistema prisional no primeiro semestre de 2016 foi de 7,7 para cada 100 mil PPL, número maior que todas as outras formas de óbito analisadas no mesmo período (mortes violentas, suicídios, mortes acidentais ou por causas desconhecidas somaram a taxa de 5,8 para cada 100 mil). Foucault (1999) já havia teorizado sobre o biopoder, uma forma de governo tipicamente moderna que age gerando vida para alguns e morte para outros. É possível que a formulação de Mbembe (2016) sobre a necropolítica seja mais adequada para a nossa realidade, por se tratar de um poder soberano que não só produz a morte como necessita da construção contínua de inimigos sobre os quais apenas o extermínio é aceitável, operando em uma lógica de guerra e de terror.

Frente a esta realidade, qual é o papel da Psicologia? Que forma de atuação queremos construir? Estaremos atrelados às demandas, muitas vezes autoritárias, do poder judiciário, ou buscaremos afirmar uma atuação ética que esteja comprometida com a garantia dos direitos humanos e com a promoção de saúde? Na prática psicológica no sistema prisional, é comum que os profissionais se encontrem, muitas vezes, afastados de recursos e do tempo necessário para uma atuação voltada para a assistência das PPL, por conta da grande demanda pela realização de exames criminológicos. Além disso, existe a questão da relação, nem sempre amigável, com outros funcionários do cárcere, sem os quais qualquer atividade pode se tornar inviável. É importante que os profissionais estejam atentos aos jogos de poder e ao modo como se estruturam as relações na prisão, na busca por linhas de fuga que levem a transformações positivas neste ambiente. Segundo Deleuze e Parnet (1998), as linhas de fuga são maneiras criativas de descobrir novos mundos, fugir ao que está instituído. No âmbito das diversas linhas que nos constituem enquanto sujeitos (relações complexas entre os grupos aos quais pertencemos, como família, escola, trabalho etc., num continuum incessante), as fugas são o que possibilitam fazer emergir o que é novo. Fugir, no entanto, não diz respeito à covardia, uma vez que "fugir não é renunciar às ações, nada mais ativo que uma fuga" (p. 30). É na busca do imprevisível e do instável que as linhas de fuga se estabelecem como maneiras de subverter a ordem preestabelecida.

\section{Saúde penitenciária: primeiras aproximações}

Um dos aspectos mais comuns do sistema prisional brasileiro é a falta de condições estruturais que garantam condições adequadas para o cumprimento das penas privativas de liberdade. $\mathrm{O}$ alto índice de doenças transmissíveis, especialmente o HIV, a tuberculose, as hepatites e as doenças dermatológicas, representam um risco constante tanto para as PPL quanto para os funcionários dos presídios e os familiares que regularmente fazem visitas às prisões. Dessa forma, contribuir para a melhoria das condições de vida nas prisões é um dos grandes desafios para a prática do psicólogo no sistema prisional.

Um primeiro ponto importante a ser destacado é a necessidade de um conhecimento aprofundado acerca do ambiente prisional e dos problemas concretos que atingem aqueles aos quais se destinarão as intervenções. Dessa forma, poderemos elaborar intervenções que considerem não apenas nossas demandas a partir do que constatamos, enquanto profissionais da equipe técnica e pesquisadores, mas também as demandas dos sujeitos que são atingidos diretamente pelo poder punitivo do Estado, de maneira que estes sejam estimulados a participar ativamente das transformações que almejam. Conforme Calatayud 
(2011), partimos de um referencial da promoção de saúde, considerando o processo de saúde/doença como resultado de múltiplas determinações, o qual não se pode abordar sem levar em consideração o papel do sujeito e das comunidades enquanto seres ativos e inseridos em determinadas condições históricas e sociais.

Não pretendemos indicar uma espécie de "fórmula" para os profissionais que lidam diretamente com a saúde das PPL. Neste artigo, faremos uma pesquisa bibliográfica acerca do tema, comentando os resultados de pesquisas e intervenções que contribuam para o desenvolvimento deste campo de conhecimento. Buscamos, com isso, oferecer subsídios para a consolidação de uma prática psicológica menos voltada para aspectos avaliativos e mais comprometida com a garantia do direito à saúde no contexto prisional.

Segundo Soares Filho e Bueno (2016), as ações de saúde no sistema prisional tiveram início com entidades religiosas. Com o advento do HIV/AIDS no Brasil, na década de 1980, alguns profissionais de saúde, em especial médicos sensíveis ao sofrimento da população prisional, iniciaram ações de prevenção e tratamento deste agravo. A partir de então, a questão da saúde penitenciária se tornou foco de ações e regulamentações de órgãos nacionais e internacionais. No Brasil, a primeira regulamentação da saúde penitenciaria foi feita pela LEP (Lei No 7.210), de 1984, que postula no título II, capítulo II, art. 11 que as PPL possuem direito à assistência material, saúde, assistência jurídica, educacional, social e religiosa. No art. 14, dispõe-se que a assistência à saúde das PPL compreende atendimento médico, farmacêutico e odontológico. A assistência psicológica não é citada nesta lei - a Psicologia só foi oficialmente inserida na equipe de assistência à saúde no sistema prisional com o PNSSP (Portaria Interministerial No 1.777, 2003) citado anteriormente, que em 2014 se transformou na "Política Nacional de Atenção Integral à Saúde das Pessoas Privadas de Liberdade no Sistema Prisional (PNAISP) no âmbito do Sistema Único de Saúde (SUS)" - Portaria Interministerial No 1 , de 2 de janeiro de 2014, que alterou a composição da equipe mínima de saúde nas prisões, passando a incluir um psicólogo na equipe de Atenção Básica (EAB) nas unidades com um efetivo carcerário de 501 a 1.220 PPL. No art. $6^{\circ}$ da PNAISP, constam os objetivos específicos desta legislação:
I - promover o acesso das pessoas privadas de liberdade à Rede de Atenção à Saúde, visando ao cuidado integral;

II - garantir a autonomia dos profissionais de saúde para a realização do cuidado integral das pessoas privadas de liberdade;

III - qualificar e humanizar a atenção à saúde no sistema prisional por meio de ações conjuntas das áreas da saúde e da justiça;

IV - promover as relações intersetoriais com as políticas de direitos humanos, afirmativas e sociais básicas, bem como com as da Justiça Criminal; e

$\mathrm{V}$ - fomentar e fortalecer a participação e o controle social.

No plano internacional, a questão da saúde penitenciária é objeto de atenção da Organização Mundial de Saúde (OMS) desde os anos 1990, tendo iniciado o Projeto Saúde no Sistema Prisional em 1995. Este projeto tem por objetivo promover a saúde pública $\mathrm{e}$ o cuidado nas prisões, articulando políticas de saúde e justiça a nível nacional e internacional. Outro objetivo é oferecer consultoria especializada para seus Estados-Membros para o desenvolvimento de sistemas de saúde nas prisões, além de oferecer apoio técnico voltado para doenças transmissíveis, em especial a tuberculose, o HIV, as hepatites e o uso de drogas ilícitas, incluindo pressupostos da redução de danos e da saúde mental (Gois, Santos Junior, Silveira, \& Gaudêncio, 2012).

Em 2007, a OMS divulgou o "Guia Saúde nas Prisões", no qual se consolidaram normas internacionais para a implementação de serviços de saúde em prisões de todo o mundo. Nele constam os princípios de que as PPL devem ter os mesmos direitos à saúde que as pessoas que vivem em liberdade, e que, ao sair da prisão, não devem estar em um estado pior do que quando entraram (WHO, 2007). Apesar das regulamentações existentes, a garantia do direito à saúde encontra sérios problemas para ser efetivada nas prisões do Brasil e ao redor do mundo. Nos países onde há grande desigualdade social, a oferta de serviços de saúde costuma ser prejudicada e não estar disponível para a maior parte da população. Com relação às PPL, a situação geral dos serviços de saúde é agravada pelos aspectos comuns à maioria das prisões, tais como: espaços insalubres e superlotados, poucos pro- 
fissionais da segurança e da área técnica com relação ao número de PPL, dificuldade de locomoção das PPL para os hospitais disponíveis da comunidade, dentre outros fatores.

Ao comentar a legislação brasileira sobre saúde penitenciária, Batista e Silva (2016) destaca que tanto o PNSSP quanto a PNAISP são políticas de caráter interministeriais que envolvem o Ministério da Justiça e o Ministério da Saúde. No entanto, ao sairmos do âmbito federal em direção ao plano estadual, onde se efetivam as ações de saúde penitenciária, nota-se que, na maioria das vezes, fica a cargo do órgão responsável pelo sistema penitenciário tanto a contratação de recursos humanos quanto a questão do financiamento, reservando-se às secretarias de saúde o papel de capacitadoras das equipes de saúde das unidades prisionais. A posição marginal das secretarias de saúde se reflete em uma predominância de ações voltadas para a manutenção da segurança e da ordem nas prisões, em detrimento de projetos de "reinserção social".

De acordo com Silva (2008), no ano de 2006 foram investidos $\mathrm{R} \$ 170$ milhões nos estados brasileiros para a construção de novos presídios, ao passo que, para as ações de garantia do direito à saúde, educação, geração de renda e desenvolvimento social nas prisões, foram aplicados menos de $\mathrm{R} \$ 3,8$ milhões, o que equivale a $2 \%$ do gasto em novos presídios. Este autor considera "falsa" a tensão entre saúde e segurança, esta última entendida como ausência de rebeliões, ao mesmo tempo em que a segurança das PPL, da qual o direito à saúde é um importante aspecto, é colocada em segundo plano. No mesmo sentido, dados do Mecanismo Nacional de Prevenção e Combate à Tortura (Brasil, 2017b), dão conta de que, em 2016, dos recursos disponibilizados pelo Fundo Penitenciário Nacional (Funpen) aos estados brasileiros e ao distrito federal, $52,39 \%$ foi destinado à construção de novos presídios, ao passo que $47,44 \%$ foi gasto com aparelhamento das unidades prisionais, que diz respeito à aquisição de equipamentos como veículos, armas e munição, bloqueadores de celular, equipamentos de segurança eletrônica, dentre outros. As verbas destinadas à manutenção de serviços penitenciários, formação de servidores e reinserção de pessoas presas e alternativas penais obteve a irrisória porcentagem de $0,17 \%$. Isso influi diretamente nas condições de vida nas prisões, aumentando a necessidade da implemen- tação de ações estratégicas que visem diminuir os agravos à saúde que atingem a população privada de liberdade brasileira.

\section{Saúde penitenciária no Rio de Janeiro: os "deserdados sociais"}

Minayo e Constantino (2015), em extensa pesquisa sobre as condições de vida e saúde no sistema prisional do estado do Rio de Janeiro, encontram uma situação de verdadeira calamidade. Através de entrevistas com um número considerável de PPL de todo o estado, as autoras e sua equipe constataram um número expressivo de sintomas e doenças que acometem esta população em número maior do que a população livre, em razão das condições de confinamento. Os dados incluem diversos problemas: respiratórios (rinite, sinusite, bronquite, tuberculose etc.), problemas cardíacos, do aparelho digestivo, osteomusculares, doenças dermatológicas, problemas do aparelho urinário, doenças infecciosas, entre outras. Com relação à saúde mental, é expressiva a prevalência da depressão em seus diferentes níveis (leve, moderada e severa), além de sintomas como estresse, irritabilidade, uso de drogas ilícitas e medicações psiquiátricas sem receita médica, prevalência maior de tentativas de suicídio e automutilações. Cerca de metade dos entrevistados relatou já ter sofrido algum tipo de violência no sistema prisional, seja violência física, psicológica, sexual etc. As PPL portadoras de doenças mentais são encaminhadas para o Hospital Roberto Medeiros, enquanto os portadores de tuberculose são transferidos das unidades prisionais em que se encontram para o Sanatório Penal.

Uma queixa comum ouvida pelas pesquisadoras diz respeito à ociosidade. As PPL reclamam da falta de trabalho disponível e de atividades recreacionais e de estudo. Além das poucas opções de trabalho oferecidas a uma minoria de PPL, as atividades mais comuns costumar ser: assistir televisão, praticar esportes, conversar entre si e participar de atividades religiosas. As mulheres recebem menos visitas de companheiros e familiares do que os homens, e apresentam níveis maiores de depressão, assim como utilizam mais remédios psiquiátricos sem prescrição médica. Por outro lado, a situação de superencarceramento intensifica os conflitos interpessoais e dificulta a convivência. Numa cidade quente como o Rio de Janeiro, especialmente nos meses do verão, as altas temperaturas tornam as celas superlotadas ambientes insuportá- 
veis, segundo relatos das PPL (Minayo, \& Constantino, 2015). A falta de abastecimento regular de água é também um sério problema que atinge esta população. No caso de alguns presídios do Rio de Janeiro, a água é disponibilizada apenas uma vez por dia, quando as PPL tomam banho e fazem estoque para sua utilização durante o dia. No entanto, este estoque geralmente é insuficiente e não são raros os problemas decorrentes de vários dias sem água. As celas em geral possuem apenas um banheiro, mesmo que estejam superlotadas. Muitas não possuem vaso sanitário, e as PPL utilizam um buraco no chão, conhecido como "boi". Por conta da falta de água, a "descarga" consiste em jogar dois pequenos baldes de água.

Ao analisar a percepção das PPL sobre o atendimento dos serviços de saúde que teoricamente estão à sua disposição, as autoras concluem que a assistência à saúde, na prática, está subordinada ao setor de segurança e dele depende. O setor da segurança é o verdadeiro responsável pelo fluxo de atendimentos, indo na contramão do que é preconizado pela PNAISP no âmbito do SUS (Minayo, \& Constantino, 2015). Além da precariedade dos encaminhamentos para a rede pública de saúde, devido, principalmente, à precariedade de transporte, inexistem esforços de prevenção de doenças. Com relação ao transporte, este é realizado nos mesmos veículos utilizados para levar outras PPL para audiências no tribunal ou para transferência entre presídios - os camburões. São diversos os relatos de violências e maus-tratos no interior destes veículos, expondo as PPL, inclusive gestantes, deficientes e pessoas com quadros agudos a situações degradantes (Minayo, \& Constantino, 2015).

\section{Adoecimento e saúde na prisão: limites e perspectivas}

Ao abordar as condições de saúde dos internos do sistema prisional inglês, De Viggiani (2007) aponta para as condições estruturais do próprio sistema enquanto as principais propiciadoras de agravos à saúde. Apesar de, assim como no Brasil, a maioria das PPL inglesas terem vindo das classes mais pobres e, portanto, terem tido pouco acesso a serviços de saúde durante a vida, o autor ressalta fatores como a superlotação das celas, as deficiências no atendimento prestado pelas equipes de saúde e a própria arquitetura das prisões como fatores de risco para os prisioneiros. Este autor conclui que, sem mudanças radicais na forma como são projetadas as prisões e na forma como são tratadas as PPL, a ideia de uma "saúde penitenciária" permanece uma contradição de termos. Em outro estudo, Dolan et al. (2016) ressaltam a maior incidência de doenças como o HIV, a tuberculose, a hepatite $\mathrm{C}$ e a hepatite $\mathrm{B}$ em prisioneiros de todo o mundo. Os autores indicam que para além das condições estruturais das prisões em diferentes países - a questão do encarceramento de usuários problemáticos de drogas vem crescendo nas últimas décadas e influenciando negativamente os indicadores de saúde pública nesta população e nas suas respectivas comunidades e países. É destacada a necessidade do desencarceramento destes usuários, com o fim de melhorar estes indicadores e tratar dos usuários fora da esfera penal.

Podemos dizer que os efeitos do encarceramento atingem não apenas as PPL, mas toda a rede de relacionamentos anterior à prisão, em especial suas famílias. Em uma pesquisa sobre o acesso à saúde de mulheres presas do Distrito Federal e a busca de suas famílias por direitos através de políticas sociais, Pereira (2016) comenta as "narrativas do cansaço" presentes nos relatos de familiares e PPL. Estar cansado, nas entrevistas realizadas, aparece como uma narrativa comum que diz respeito às inúmeras dificuldades de seguir a vida mantendo os laços familiares da mulher presa. Os laços familiares aparecem como um importante vínculo das mulheres encarceradas, tendo em vista que muitas possuem filhos e precisam deixá-los com suas mães ou outros parentes, que, nas visitas, atualizam a mulher sobre a vida fora da prisão e de alguma forma mantém seu controle sobre o cuidado dos filhos. Por outro lado, a ausência da mulher-mãe de sua casa em geral desestabiliza a dinâmica das relações familiares, onde as que ficam responsáveis por cuidar dos filhos relatam uma sobrecarga de funções, sendo necessário a muitas delas largar o emprego para poder ajudar a mulher privada de liberdade e seus filhos. O "auxílio-reclusão", benefício legal recebido pelas famílias das PPL quando trabalhavam antes da prisão e contribuíam para o Instituto Nacional do Seguro Social (INSS), dificilmente é recebido pelas famílias. São inúmeros os relatos de mulheres que buscam, sem sucesso, esse benefício. O Estado aparece, na representação das mulheres privadas de liberdade e das visitantes, como aquele que daria soluções (bolsa família, auxílio-reclusão, defensoria pública etc.), mas que, na prática, apresenta diversos entraves e burocracias que afastam quem mais precisa deles. 
Em pesquisa sobre os direitos reprodutivos das mulheres no sistema prisional, Diuana, Ventura, Simas, Larouzé e Correa (2016) comentam a deslegitimação da maternidade das mulheres privadas de liberdade, aliada a um certo moralismo de alguns funcionários das prisões em relação aos relacionamentos afetivos-sexuais destas mulheres, que julgam ser uma tentativa de engravidar para conseguir "benefícios". Apesar de o Brasil ser signatário das Regras de Bangkok (ONU), que reconhecem os problemas específicos das mulheres presas e a necessidade de encontrar meios para sua solução, Diuana et al. (2016) alertam para perigo, sempre presente, de os discursos sobre a prevenção da saúde sexual e reprodutiva-especialmente no que concerne à "gravidez irresponsável" e ao risco de infecção por doenças sexualmente transmissíveis - instrumentalizarem práticas que desconsideram a autonomia destas mulheres, "estruturando ações de saúde onde não há espaço para a escuta de mulheres nem para um trabalho que favoreça tomada de decisões mais livres de constrangimentos, tanto para engravidar como para não fazê-lo" (p. 2046).

\section{Saúde penitenciária: desafios para a práxis psicológica}

Considerando a complexidade dos problemas abordados, a prática psicológica se situa no contexto de alguns paradoxos e tensões: castigar ou "reeducar", avaliar/examinar ou prestar assistência, fomentar autonomia no espaço de privação de liberdade, dentre outros. Estes paradoxos fundamentam diferentes perspectivas para a prática psicológica no sistema prisional, mais ou menos afeitas à garantia de direitos. Queremos frisar que, como trabalhadores e pesquisadores que intervém sobre a realidade prisional brasileira, nossas constatações e intervenções possuem sempre, em última instância, um caráter político. Isso porque a Psicologia, como ciência social aplicada, estará sempre aliada a uma determinada concepção de sujeito e de sociedade, que legitima as práticas profissionais. Frente à impossibilidade de um encontro "neutro" entre Psicologia e sistema prisional, nos cabe decidir quais posicionamentos teóricos, éticos e políticos embasarão nossa práxis, a despeito das muitas limitações impostas pela realidade da prisão. Nesse contexto, assumindo o compromisso ético-político com a garantia dos direitos humanos e com a redução dos danos dos efeitos do encarceramento, a pergunta mais óbvia e, ao mesmo tempo, mais difícil de ser respondida é: como reduzir o sofrimento daqueles que estão mais vulneráveis à violência institucional? Como promover saúde no sistema prisional? É possível melhorar as condições de vida e de saúde nas prisões?

Em um estudo sobre a oferta de serviços de saúde em uma prisão da Costa do Marfim, Marcis (2016) formula a seguinte questão: Quem governa a saúde nas prisões? Na prisão estudada pelo autor, os serviços de saúde eram gerenciados por uma enfermeira e um chefe do pavilhão (que é uma PPL escolhida pelos demais), onde se concentravam os atendimentos, enquanto a maior parte destes era feita pelas próprias PPL, chamados de "faxinas da saúde" e que não necessariamente possuíam conhecimentos e experiência em serviços de saúde. $O$ autor descreve as diversas tensões próprias daquele presídio que também se faziam presentes no atendimento à saúde. Por conta de serem os "faxinas" os principais responsáveis pelos atendimentos, muitas suspeitas recaíam sobre os mesmos, o que já afastava a procura dos serviços: $\mathrm{O}$ que faziam antes do aprisionamento? Teriam condições e conhecimento necessário para prestar atendimentos de qualidade? Outro problema era a seleção daqueles que seriam atendidos, uma vez que os serviços de saúde, na lógica da prisão, acabam sendo vistos como uma "regalia", ou seja, algo disponível apenas às PPL que possuem condições de pagar por eles. Uma vez que a prisão prestava apenas assistência e recursos mínimos, todo o resto poderia ser comercializado, o que também é uma realidade no Brasil. Por conta de grande parte dos serviços da prisão serem "privatizados" - comercializados geralmente pelas próprias PPL - o acesso à saúde acabava por entrar também nesta lógica, na qual os chefes de cada setor escolhiam quem iria ser atendido pelos serviços de saúde em cada dia (sendo o máximo de dez PPL por dia). Cabe um paralelo com a realidade do Rio de Janeiro, onde os encaminhamentos para os serviços de saúde são bastante parecidos, ficando a cargo dos "faxinas" transportar os "catuques" - pedaços de papel com nome, número de identidade e a localização da cela das PPL que solicitarem atendimento de saúde ou outro tipo de atendimento (jurídico, do serviço social, da Psicologia, dentre outros).

O autor trabalha com a ideia da existência de uma "dupla governança da prisão" (Marcis, 2016), que diz respeito à tensão entre segurança e saúde e também à governança concreta das prisões, que é regida tanto pelo Estado - representado pelos funcionários do cárcere e pela legislação penal - quanto pelas 
próprias PPL, que se organizam no espaço prisional, elegem suas lideranças e participam ativamente da criação e manutenção das "leis" da prisão. O estudo volta-se para a análise da eleição de um novo chefe do pavilhão dos serviços de saúde, bem como para a tentativa da enfermeira-chefe de criar normas fixas para os serviços de saúde (horários pré-definidos, rotinas de atendimento, pessoal de sobreaviso etc.), fortalecendo-o a partir de uma lógica sanitária. No entanto, o estudo de caso relevou que as tensões entre os diversos interesses envolvidos na manutenção do status quo daquela unidade prisional foram os determinantes do rumo dos serviços de saúde. O novo chefe do pavilhão da saúde foi escolhido por meio de um consenso entre a direção do presídio e a opinião das PPL, indo contra a indicação da enfermeira. Da mesma forma, as rotinas por ela implantadas não obtiveram sucesso. $\mathrm{O}$ acesso à saúde permaneceu sendo mercantilizado e, portanto, restrito a uma minoria.

$\mathrm{O}$ autor conclui o artigo enfatizando a necessidade de reconhecimento das normas e "leis" inerentes ao sistema prisional, sem o qual toda intervenção encontrará sérias dificuldades. Outro ponto importante é a diferença entre a saúde pensada na vida em liberdade e dentro do cárcere. As particularidades do ambiente prisional exigem uma abordagem em saúde que reconheça fatores complexos, tais como a perda da autonomia na privação de liberdade, as tensões que decorrem dos relacionamentos interpessoais e institucionais, os significados das diferentes práticas para os diferentes grupos, dentre outras questões. Um dos grandes entraves à garantia do direito à saúde no sistema penitenciário é o não reconhecimento das PPL como sujeitos de direitos, legitimando o desrespeito sistemático à legislação que regula o sistema prisional. Em países onde os serviços de saúde pública não são ofertados de maneira plena e com qualidade para a população como um todo, a questão da saúde penitenciária tende a ser vista como menos importante, desnecessária ou mesmo ilegítima. O reconhecimento do modo como se dão as relações em sistemas prisionais específicos - ligadas ao contexto socioeconômico e cultural onde estão inseridas - cria as condições para que seja possível a elaboração de propostas de intervenção que atendam às demandas concretas da população ao qual se destina.

Abordar pragmaticamente a saúde em meio carcerário é antes de tudo reconhecer que, em países onde o sistema de saúde é falho e os recursos financeiros limitados, a prisão permanece um objeto de engajamento político pouco legítimo. É também admitir que a promoção da saúde em meio carcerário repousa sobre um paradoxo: ela se apoia na autonomia num contexto de privação de liberdade. Este reconhecimento prévio à ação se situa em diferentes escalas: na nacional a nível dos atores políticos; na da prisão, a nível da população carcerária, dos detentos e dos agentes carcerários. Nos dois casos, melhor que defender noções universais abstratas e não situadas, trata-se de abrir um espaço possível tendo por objetivo o reconhecimento da experiência e das imposições dos diferentes atores, para uma governança real da saúde. Tal processo deveria, logicamente, levar a estender a questão da governança em saúde na prisão fora dos muros do espaço carcerário para pensar a continuidade dos cuidados após o encarceramento, o futuro de educadores pares formados na prisão uma vez em liberdade, e inventar uma abordagem "dessanitarizada" da saúde em prisão (Marcis, 2016, p. 2018, grifo nosso).

Marcis (2016) afirma ainda a necessidade de que as ações voltadas às PPL se destinem também aos guardas da prisão. No entanto, apesar do reconhecimento do sofrimento destes funcionários a muitos dos agravos que as PPL estão expostas, a logística destas intervenções pode se tornar problemática. "Se por um lado elas [as intervenções] devem ser simultâneas, não podem se dirigir ao mesmo público ao mesmo tempo. Além disso, elas pressupõem recursos mais elevados" (Marcis, 2016, p. 2015). Apesar das dificuldades de serem elaboradas intervenções que contemplem tanto as PPL quanto os funcionários do cárcere, em especial os agentes penitenciários, ressaltamos a importância do diálogo e do cuidado com estes profissionais. Em revisão sobre o estresse no trabalho dos agentes penitenciários, Bezerra, Assis e Constantino (2016) encontram níveis elevados de estresse e situações de esgotamento (burnout) em uma grande parte destes trabalhadores, principalmente quando estes se veem expostos e sem os recursos necessários para exercer seu trabalho, além da tensão existente entre punir e educar, que atravessa a prática profissional desta categoria.

Diuana et al. (2008) trazem um relato de uma pesquisa-ação realizada em três presídios e dois hospitais especializados (um voltado para o tratamento da tuberculose e o outro para o HIV) do Rio de Janeiro, dis- 
cutindo principalmente a percepção dos agentes penitenciários sobre as condições de trabalho e saúde no interior do cárcere. Os autores realizaram entrevistas com PPL e agentes penitenciários e encontros grupais com os agentes. Os grupos foram possibilitados pelo dispositivo "café da manhã", por meio do qual, durante a troca de turnos e em reuniões totalmente informais na rotina institucional, foi possível agrupar um número considerável de agentes e discutir questões pertinentes e temores relacionados à prática profissional de cada um. Agentes penitenciários e PPL destacam como uma das principais preocupações a possibilidade de serem alvo de violência física, em decorrência de seus vínculos com a prisão. As condições insalubres das instalações prisionais são percebidas como algo inerente ao ambiente, gerando uma sensação de impotência quanto a sua melhoria (Diuana et al., 2008). Com relação à proteção contra a contaminação por doenças, os autores encontraram três estratégias básicas utilizadas pelos agentes: identificar os doentes, principalmente os homossexuais que poderiam ser portadores de AIDS; manter distância das PPL; prender a respiração ao entrar nas celas ou ao abrir o camburão. Há também o medo de entrar em contato com o sangue dos detentos em situações de brigas entre eles. As PPL aparecem na representação dos agentes penitenciários como os principais transmissores de doenças, sendo a prática profissional realizada sem recursos eficazes que os protejam de contaminações. Em consonância com outros autores que estudam a saúde penitenciária, foi identificado um modo de acesso aos serviços de saúde permeado por critérios estranhos à saúde em si, gerando uma desvalorização das queixas das PPL, com poucas chegando efetivamente a conseguir atendimento. Tal impasse pode ser melhor compreendido a partir das relações entre agentes de segurança e detentos, em que o cuidado frequentemente é associado à fraqueza, rebaixamento e submissão, sendo relegado a segundo plano em prol da afirmação da imagem de força e poder que é valorizada por ambas as partes da relação.

Mesmo com as dificuldades relatadas pelos autores na concretização da referida intervenção, são citados os pontos positivos proporcionados pela mesma: a desconstrução das ideias estereotipadas da representação das PPL como a "fonte do mal"; o fato de a discussão sobre as diversas questões relacionadas aos riscos que todos estão expostos ter favorecido uma maior implicação dos agentes penitenciários com as questões de saúde, além de frisar a necessidade de uma maior interação com os outros profissionais do sistema prisional, em especial aqueles ligados à saúde e à educação (Diuana et al., 2008). O diálogo com os diversos atores que convivem no cárcere se configura como instrumento para o conhecimento e minimização das questões problemáticas ligadas ao cárcere. A partir da boa resposta obtida pelos agentes de segurança penitenciária a esta intervenção, os autores concluem que a "descrença, o sentimento de abandono e de desvalorização dos profissionais que atuam nas unidades pode ser reduzido por um trabalho que contemple a escuta e a construção conjunta de soluções que possam ser assumidas pelo grupo" (Diuana et al., 2008, p. 1894).

Podemos dizer que, para além de intervenções que visem de forma direta os processos de saúde e adoecimento, a prática psicológica pode contribuir para a redução de danos dos efeitos do encarceramento por meio de múltiplas estratégias, a depender dos recursos e da criatividade de cada profissional. Consideramos que a arte e a cultura podem se constituir como importantes aliados na difícil tarefa e promover saúde mental nos ambientes de privação de liberdade. $O$ recurso à arte (em suas diferentes modalidades: música, artes visuais ou plásticas, literatura, teatro/cinema, etc.) pode potencializar afetos e estimular a criatividade, mesmo na dura realidade prisional. Bandeira (2012) traz o relato de oficinas de leitura e contação de histórias realizadas em presídios masculinos e femininos. Por meio dos relatos de participantes das oficinas, fica evidente a potência de práticas que buscam afirmar, por meio do contato com a arte, as singularidades. Isso se torna especialmente importante quando temos em vista os efeitos do encarceramento que vão muito além da privação de liberdade, abarcando diversos âmbitos das relações sociais e da subjetividade. Cabe a nós, "profissionais de saúde, que trabalhamos nas prisões, [...] lutar pela transformação de práticas perversas, investindo em movimentos criativos e inventivos que potencializam a vida, a solidariedade e cooperação como instrumentos de resistência" (Bandeira, 2012, p. 147).

É interessante também o relato de Hoffmann (2012) acerca de um concurso de obras de arte realizado na Penitenciária de Florianópolis. A ideia surgiu da inquietação de diversos profissionais que, por meio de doações e contando com a cooperação de diretores e inspetores, obtiveram êxito no processo e até mesmo superaram expectativas em termos de adesão dos internos e qualidade das obras. Nas criações artísticas, muitos talentos 
foram descobertos, abrindo a percepção para as potencialidades de cada um, tanto por parte dos presidiários quanto dos trabalhadores. Outro resultado positivo desta intervenção foi a exposição, fora do cárcere, dos melhores trabalhos, que pôde inclusive ser divulgada em jornais e noticiários de televisão. Isso certamente contribuiu para a desconstrução da imagem dos presidiários apenas como delinquentes, mostrando seu lado sensível e potencial artístico. Consideramos também ser este um importante papel a ser desempenhado pela Psicologia nas prisões: o de alguma forma informar a sociedade sobre estas experiências positivas que ocorrem no cárcere, propiciando trocas entre o dentro e o fora, uma vez que o que se costuma noticiar são fatos negativos como motins ou rebeliões.

Cabe-nos, portanto, (re)pensar o papel que a Psicologia pode desempenhar nas prisões, indo além da lógica avaliativa dos exames criminológicos. Para isto, é imprescindível que toda prática seja contextualizada e conheça os principais problemas que permeiam as relações sociais no cárcere, assim como as demandas das PPL. Mesmo diante das limitações decorrentes da precariedade das instalações prisionais, linhas de fuga se tornam possíveis a partir do redirecionamento ético-político em direção à garantia de direitos e de bem-estar, possibilitando a criação de espaços de escuta, de acolhimento e também a formulação de estratégias de enfrentamento aos efeitos mortificantes gerados pelo aprisionamento.

\section{Considerações finais}

A Psicologia foi inserida oficialmente no sistema prisional brasileiro para instrumentalizar o princípio da individualização das penas na Lei de Execuções Penais de 1984, participando das equipes de saúde penitenciária apenas em 2003 com a promulgação do Plano Nacional de Saúde no Sistema Penitenciário (PNSSP). No entanto, ainda hoje os profissionais da Psicologia se encontram atrelados a demandas avaliativas, por meio da exigência de realização dos exames criminológicos. Como afirma Rauter (2010), a Psicologia não adentrou no cárcere para "humanizá-lo", mas para contribuir com as estratégias punitivas do Estado. Isso explica, em parte, a dificuldade de muitos psicólogos em assumirem uma postura crítica com relação às demandas do poder judiciário, que insiste em solicitar a produção incessante de laudos e pareceres que sirvam para subsidiar as decisões judiciais. Muitos profissionais encontram dificuldades de imaginar formas de atuação mais inventivas, para além da prática instituída legalmente da produção dos exames criminológicos.

No entanto, a realidade das prisões brasileiras encontra-se permeada por fatores perversos, como: violações sistemáticas de direitos, torturas e tratamentos degradantes, epidemias e inúmeras mortes causadas por doenças tratáveis. Como fechar os olhos a esta realidade? Tais fatores não representam um "erro" do sistema de justiça criminal, mas, antes, constituem o próprio modus operandi das políticas de segurança pública e de execução penal, em que a morte e o extermínio se tornaram não apenas aceitáveis, mas foram naturalizados pelos operadores do direito, pelos técnicos da execução penal e pela sociedade como um todo. Isso nos indica a necessidade de uma crítica radical da prisão e seu intento paradoxal de "ressocializar" através da privação de liberdade, escondendo seus objetivos, velados ou não, de realizar uma gestão penal e militarizada da pobreza (Wacquant, 2011). As prisões reproduzem a violência que supostamente visam combater, sem que seja comprovada sua eficácia na prevenção de novos crimes. É urgente que se fortaleçam mecanismos que privilegiem as penas alternativas, reconhecendo os altos custos humanos e sociais do encarceramento, restringindo-o aos casos de violência real contra a vida. Nossas análises e práticas devem demonstrar os paradoxos da execução penal, como forma de resistência ao punitivismo que, cada vez mais, aumenta as cifras do sistema penal brasileiro e aprofunda as situações de violação de direitos.

Por outro lado, uma vez inseridos no contexto prisional, suas condições de vida desumanas indicam a necessidade de focarmos nossa atuação na criação de estratégias de redução de danos por meio de intervenções contextualizadas e atentas às demandas, queixas e também às potências das PPL. Os serviços de saúde no sistema prisional devem se basear nos princípios do SUS, com equipes que ultrapassem o viés curativo e favoreçam a prevenção e a promoção em saúde. Este empenho poderá ser facilitado com o apoio das secretarias estaduais de saúde, com investimentos e mobilização para a implantação das equipes de atenção básica previstas na PNAISP e para a realização de intervenções e treinamentos. Enquanto psicólogos inseridos no contexto prisional, devemos fortalecer práticas de cuidado na perspectiva da redução de danos, buscando parceiros dentro e fora das prisões que ajudem a minimizar os efeitos perversos do encarceramento. 
A Psicologia, enquanto ciência e profissão voltada para a garantia de direitos e para a promoção da saúde, pode contribuir para a melhoria das condições de vida nos cárceres brasileiros, criando estratégias de escuta das PPL que buscarem este serviço, práticas grupais ou ações voltadas para a promoção de saúde que envolvam outros atores dentro ou fora do sistema prisional, como por exemplo, profissionais que desenvolvam atividades artísticas e culturais, uma vez que a arte e a cultura podem ser ferramentas potentes para a produção de uma subjetividade que leve em conta a valorização da vida e não da morte. Para tanto, é imprescindível que a categoria reavalie constantemente e de forma crítica sua própria atuação e seus pressupostos teórico-práticos, sob o risco constante de legitimar práticas punitivas desumanas que nada contribuem para a "reinserção social" ou para a prevenção de novos delitos, retroalimentando o ciclo da violência que perpassa nossa sociedade. As PPL não são sujeitos completamente afastados do convívio social, tendo em vista que recebem visitas de companheiros afetivos, filhos e amigos, além do contato com os funcionários do cárcere e voltarão, em algum momento, ao convívio social. Dessa forma, os diversos problemas de saúde que acometem a população carcerária devem ser considerados urgências humanitárias e prioridades da saúde pública, tendo em vista o risco de adoecimento e, no limite, de morte a que está submetida a população carcerária brasileira.

É importante frisar que, mesmo que a realidade das prisões brasileiras fosse diferente do que é hoje, com locais menos insalubres e com uma população carcerária reduzida, a privação de liberdade continuaria sendo, em si mesma, um vetor de sofrimento. Ainda que, como psicólogos, busquemos muitas vezes intervenções pontuais, práticas individuais ou com pequenos grupos na busca por mudanças subjetivas ou micropolíticas, não podemos perder de vista que a perda da liberdade é um dos grandes adversários de uma vida saudável. Dessa forma, devemos reconhecer que a maneira mais eficaz de reduzir os danos à saúde causados pelo aprisionamento é pela via do desencarceramento. Nesse sentido, os movimentos Agenda Nacional pelo Desencarceramento, liderado pela Pastoral Carcerária (2014) e a Frente Estadual pelo Desencarceramento do Rio de Janeiro (Sansão, 2017) possuem propostas importantes para a redução do processo de encarceramento em massa, dentre elas, a efetivação das Audiências de Custódia (AC), um importante dis- positivo legal para a garantia da rápida apresentação do preso a um juiz nos casos de prisões em flagrante, de modo que a pessoa presa seja ouvida, assim como o Ministério Público, a Defensoria Pública ou advogado do preso, e seja também observado se há sinais de tortura. Tal dispositivo já está previsto em pactos e tratados internacionais assinados pelo Brasil, como o Pacto Internacional de Direitos Civis e Políticos e a Convenção Interamericana de Direitos Humanos, conhecida como Pacto de San Jose. As AC têm sido implementadas paulatinamente nos estados brasileiros e esperamos que, desse modo, os juízes, analisando as condições e a natureza do delito, possam aplicar penas alternativas à prisão com maior frequência. Infelizmente, a pena privativa de liberdade ainda tem sido mantida como regra na AC, como demonstra o Relatório de acompanhamento das AC da Defensoria Pública do Rio de Janeiro, publicado em julho de 2018, referente ao período de setembro de 2016 a setembro de 2017 (Estado do Rio de Janeiro, 2018). Apesar disso, espera-se que, aos poucos, os juízes possam reverter esses dados e compreendam a importância da AC como uma importante ferramenta para a redução dos níveis de encarceramento.

E nós, psicólogos, o que temos a ver com isso? A partir da constatação dos efeitos perversos do encarceramento, aliados às péssimas condições do sistema prisional brasileiro, nosso papel é o de contribuir para a promoção de saúde neste ambiente, colocando teoria e práxis a serviço daqueles que são atingidos de forma mais contundente pela violência de Estado. Como demonstrado pela análise da literatura da área da saúde penitenciária, mesmo com recursos limitados é possível formular intervenções que contribuam para a redução dos agravos à saúde física e mental das PPL e dos funcionários do cárcere. Afirmar o direito à saúde e à vida no interior das prisões é um compromisso ético-político necessariamente contrário à lógica punitivista do Estado que legitima a segregação, a retirada de direitos e, no limite, a morte de determinadas parcelas da população. Como preconiza o Código de Ética Profissional do Psicólogo (Conselho Federal de Psicologia, 2005), nossas práticas devem estar comprometidas com a defesa intransigente dos direitos humanos, baseando nosso trabalho no respeito e na promoção da liberdade, da dignidade, da igualdade e da integridade do ser humano. Cabe a nós, psicólogos, contribuir para a promoção da saúde e da qualidade de vida das pessoas e das coletividades em todos os espaços de trabalho, inclusive nas prisões. 


\section{Referências}

Anistia Internacional (2018, 18 de janeiro). 25\% dos assassinatos no município do Rio de Janeiro em 2017 foram cometidos pela polícia. Recuperado de https://anistia.org.br/noticias/25-dos-assassinatos-rio-de-janeiro-em-2017-foram-cometidos-pela-policia/

Bandeira, M. M. B. (2003). "Seu castigo é este”: Comissão Técnica de Classificação, Gestão Prisional e prática (interdisciplinar?) do Psicólogo (Monografia). Universidade do Estado do Rio de Janeiro, Rio de Janeiro, RJ, Brasil.

Bandeira, M. M. B (2012). Sistema prisional: Contando e recontando histórias: As oficinas de contação de histórias como processos inventivos de intervenção. Curitiba, PR: Juruá.

Bandeira, M. M. B., Almeida, O., \& Santos, V. (2014). A inserção, trajetória e práticas dos psicólogos do sistema prisional do Rio de Janeiro: Um resgate histórico. São Paulo, SP: Lexia.

Bandeira, M. M. B., Camuri, A. C., \& Nascimento, A. R. (2011). Exame criminológico: Uma questão ética para a psicologia e para os psicólogos. Mnemosine, 7(1), 27-61.

Barros, V. A., \& Amaral, T. V. F. (2016). O trabalho do(a) psicólogo(a) no sistema prisional. In F. França, P. Pacheco, \& R. T. Oliveira (Orgs.), O trabalho da(o) psicóloga(o) no sistema prisional: Problematizações, ética e orientações (pp. 55-72). Brasília, DF: Conselho Federal de Psicologia.

Batista e Silva, M. B. (2016). Emergência de uma política, extinção de uma coordenação: Sobre a gestão da saúde penitenciária no Brasil. Ciência \& Saúde Coletiva, 17(5), 2021-2030. https://doi.org/10.1590/1413-81232015217.00162016

Bezerra, C.M.,Assis, S. G., \& Constantino, P. (2016). Sofrimentopsíquicoeestressenotrabalhodeagentes penitenciários:uma revisão da literatura. Ciência \& Saúde Coletiva, 21(7), 2135-2146. http://dx.doi.org/10.1590/1413-81232015217.00502016

Bocco, F. (2013). A psicologia no Estado Penal: possibilidades e estratégias para subverter a judicialização. In: C. Coimbra, L. S. M. Ayres, \& M. L. Nascimento (Orgs.), Pivetes: Encontros entre a psicologia e o judiciário (pp. 116-123). Curitiba, PR: Juruá.

Brasil. Ministério de Direitos Humanos. Secretaria Nacional de Cidadania. Mecanismo Nacional de prevenção e Combate à Tortura. (2017b). Relatório Temático: FUNPEN e Prevenção à Tortura - As ameaças e potenciais de um fundo bilionário para a prevenção à tortura no Brasil. Brasília, DF: o autor.

Brasil. Ministério da Justiça e Segurança Pública. Departamento Penitenciário Nacional. (2017a). Levantamento nacional de informações penitenciárias - Infopen. Brasília, DF: o autor.

Calatayud, F. M. (2011). A psicologia e a promoção da saúde: Do que necessitamos, o que temos e o que podemos fazer. In: J. C. Sarriera (Org.), Saúde comunitária: Conhecimentos e experiências na América Latina (pp. 19-26). Porto Alegre, RS: Sulina.

Carvalho, S. (2011). O papel da perícia psicológica na execução penal. In: H. S. Gonçalves, \& E. P. Brandão (Orgs.), Psicologia jurídica no Brasil (pp. 175-197). Rio de Janeiro, RJ: Nau.

Conselho Federal de Psicologia (2005). Código de ética do Psicólogo. Brasília, DF: o autor.

Costa, F., \& Bianchi, P. (2017, 14 de agosto). “Massacre silencioso”: doenças tratáveis matam mais que violência nas prisões brasileiras. Uol. Notícias. Recuperado de https://noticias.uol.com.br/cotidiano/ultimas-noticias/2017/08/14/ massacre-silencioso-mortes-por-doencas-trataveis-superam-mortes-violentas-nas-prisoes-brasileiras.htm

D’Elia Filho, O. Z. (2015). Indignos de vida: A forma jurídica da política de extermínio de inimigos na cidade do Rio de Janeiro. Rio de Janeiro, RJ: Revan.

De Viggiani, N. (2007). Unhealthy prisons: exploring structural determinants of prison health. Sociology of Health \& Illness, 29(1), p. 115-135. https://doi.org/10.1111/j.1467-9566.2007.00474.x

Deleuze, G., \& Parnet, C. (1998). Diálogos. São Paulo, SP: Escuta.

Diuana, V., Lhuilier, D., Sánchez, A. R., Amado, G., Araújo, L., Duarte, A. M. et al (2008). Saúde em prisões: Representações e práticas dos agentes de segurança penitenciária no Rio de Janeiro, Brasil. Cadernos de Saúde Pública, 24(8), 1887-1896. https://doi.org/10.1590/S0102-311X2008000800017

Diuana, V., Ventura, M., Simas, L., Larouzé, B., \& Correa, M. (2016). Direitos reprodutivos das mulheres no sistema penitenciário: Tensões e desafios na transformação da realidade. Ciência \& Saúde Coletiva, 21(7), 2041-2050. https://doi.org/10.1590/1413-81232015217.21632015 
Dolan, K. Wirtz, A. L., Moazen, B., Ndeffo-mbah, M., Galvani, A., Kinner, S. A. et al. (2016). Global burden of HIV, viral hepatitis, and tuberculosis in prisoners and detainees. The Lancet, 388(10049), 1089-1102. https://doi. org/10.1016/S0140-6736(16)30466-4

Estado do Rio de Janeiro (2018). Defensoria Pública. Relatório $2^{\circ}$ ano das audiências de custódia no Rio de Janeiro. Rio de Janeiro: o autor. Recuperado de http://www.defensoria.rj.def.br/uploads/arquivos/c2f0263c194e4f67a218c75cfc9cf67e.pdf

Foucault, M. (1999). Em defesa da sociedade: Curso no Collège de France (1975-1976). São Paulo, SP: Martins Fontes.

Foucault, M. (2014). Vigiar e punir. Petrópolis, RJ: Vozes.

Gois, S. M., Santos Junior, H. P. O., Silveira, M. F. A., \& Gaudêncio, M. M. P. (2012). Para além das grades e punições: uma revisão sistemática sobre saúde penitenciária. Ciência \& Saúde Coletiva, 17(5), 1235-1246. http://dx.doi. org/10.1590/S1413-81232012000500017

Hoffmann, M. F. (2012). Fazendo arte na prisão. In: S. Martins, A. Beiras, \& R. M. Cruz (Orgs.), Reflexões e experiências em psicologia jurídica no contexto criminal/penal (pp. 175-198). São Paulo, SP: Vetor.

Karam, M. L. (2011). Psicologia e sistema prisional. Revista EPOS, 2(2).

Kolker, T. (2011). A atuação dos psicólogos no sistema prisional. In: H. S. Gonçalves, \& E. P. Brandão (Orgs.), Psicologia jurídica no Brasil (pp. 199-251). Rio de Janeiro, RJ: Nau.

Lei No 7.210, de 11 de julho de 1984. Institui a Lei de Execução Penal. Diário Oficial da União.13 jul. 1984.

Lei No 10.792, de 01 de dezembro de 2003. Altera a Lei no 7.210, de 11 de junho de 1984 - Lei de Execução Penal e o Decreto-Lei no 3.689, de 3 de outubro de 1941 - Código de Processo Penal e dá outras providências. Diário Oficial da União. 2 dez. 2003.

Marcis, F. L. (2016). A impossível governança da saúde na prisão? Reflexões a partir da MACA (Costa do Marfim). Ciência e Saúde Coletiva, 21(7), 2011-2019. http://dx.doi.org/10.1590/1413-81232015217.00162016

Mbembe, A. (2016). Necropolítica. Arte \& Ensaios, (32), 123-151. https://revistas.ufrj.br/index.php/ae/article/view/8993

Mello, I., \& Castro, J. (2018, 24 de junho). Mais de quatro detentos morrem por dia em prisões do país. O Globo. Recuperado de https://oglobo.globo.com/brasil/mais-de-quatro-detentos-morrem-por-dia-em-prisoes-do-pais-22815782?utm_source=Facebook\&utm_medium=Social\&utm_campaign=O\%20Globo

Minayo, M. C. S., \& Constantino, P. (2015). Deserdados sociais: Condições de vida e saúde dos presos do estado do Rio de Janeiro. Rio de Janeiro, RJ: Editora Fiocruz.

Pastoral Carcerária (2014). Agenda Nacional pelo Desencarceramento. São Paulo: Pastoral Carcerária. Recuperado de http://carceraria.org.br/agenda-nacional-pelo-desencarceramento

Pereira, E. L. (2016). Famílias de mulheres presas, promoção de saúde e acesso às políticas sociais no Distrito Federal, Brasil. Ciência \& Saúde Coletiva, 17(5), 2123-2134. https://doi.org/10.1590/1413-81232015217.16792015

Portaria Interministerial No 1.777, de 9 de setembro de 2003. Aprova o Plano Nacional de Saúde no Sistema Penitenciário. Diário Oficial da União. 1 out. 2003.

Portaria Interministerial № 1, de 02 de janeiro de 2014. (2014, 02 de janeiro). Institui a Política Nacional de Atenção Integral à Saúde das Pessoas Privadas de Liberdade no Sistema Prisional (PNAISP) no âmbito do Sistema Único de Saúde (SUS). Diário Oficial da União. 2 jan. 2014.

Rauter, C. (2007). Clínica e estratégias de resistência: Perspectivas para o trabalho do psicólogo em prisões. Psicologia \& Sociedade, 19(2), 42-47. https:/ / doi.org/10.1590/S0102-71822007000200006

Rauter, C. (2010). Discursos e práticas psi no contexto do grande encarceramento. In: P. Abramovay, \& V. M. Batista (Orgs.), Depois do grande encarceramento (pp. 195-205). Rio de Janeiro, RJ: Revan.

Rauter, C. (2016). O trabalho do psicólogo em prisões. In F. França, P. Pacheco, \& R. T. Oliveira (Orgs.), O Trabalho da(o) psicóloga(o) no sistema prisional: Problematizações, ética e orientações (pp. 43-53). Brasília, DF: Conselho Federal de Psicologia.

Rossotti, B. G. P., \& Bicalho, P. P. G. (2012). Por uma outra Psicologia no cárcere: Presos provisórios, processos de criminalização e produção de subjetividade. In: S. Martins, A. Beiras, \& R. M. Cruz (Orgs.), Reflexões e experiências em psicologia jurídica no contexto criminal/penal (pp. 81-108). São Paulo, SP: Vetor.

Sánchez, A., \& Larouzé, B. (2016). Controle da tuberculose nas prisões, da pesquisa à ação: A experiência do Rio de Janeiro, Brasil. Ciência \& Saúde Coletiva, 21(7), 2071-2080. https://doi.org/10.1590/1413-81232015217.08182016 
Sansão, L. (2017, 28 de janeiro). Frente Estadual pelo Desencarceramento é lançada no Rio de Janeiro. Ponte. Direitos Humanos, Justiça, Segurança Pública. Recuperado de https://ponte.org/frente-estadual-pelo-desencarceramento-e-lancada-no-rio-de-janeiro/

Silva, F. S. (2008). A cidadania encarcerada: Problemas e desafios para a efetivação do direito à saúde nas prisões. In A. Costa, J. G. Souza Júnior, M. C. Delduque, M. S. C. Oliveira, \& S. G. Dallari (Orgs.), O Direito achado na rua: Introdução crítica ao direito à saúde (pp. 241-252). Brasília, DF: CEAD, UnB.

Soares Filho, M. M., \& Bueno, P. M. M. G. (2016). Demografia, vulnerabilidade e direito à saúde da população prisional brasileira. Ciência \& Saúde Coletiva,21(7), 1999-2010 http://dx.doi.org/10.1590/ 1413-81232015217.24102015

Wacquant, L. (2011). As prisões da miséria. Rio de Janeiro, RJ: Zahar.

World Health Organization. (2007). Health in prisons: A WHO guide to essentials in prison health. Copenhagen: Organization Regional Office for Europe.

\section{Lucas Gonzaga do Nascimento}

Psicólogo pela Universidade Veiga de Almeida (UVA) e especialista em Psicologia Jurídica pela Universidade do Estado do Rio de Janeiro (UERJ).

E-mail: lucasgonzagapsi@gmail.com

(iD https://orcid.org/0000-0002-2894-9141

\section{Maria Márcia Badaró Bandeira}

Psicóloga pela Universidade Gama Filho, Mestre em Psicologia Social pela Universidade do Estado do Rio de Janeiro (UERJ) e Especialista em Psicologia Jurídica pela UERJ. Professora convidada do Curso de Especialização em Psicologia Jurídica da UERJ. Psicóloga aposentada da Secretaria de Estado de Administração Penitenciária do Estado do Rio de Janeiro. Conselheira do Conselho Federal de Psicologia (2016-2019).

E-mail: mbmarciabadaro@gmail.com

(iD https://orcid.org/0000-0002-2036-0113

Endereço para envio de correspondência:

Rua São Francisco Xavier, 524, sala 10005, bloco B, Maracanã . CEP: 20550-013. Rio de Janeiro - RJ. Brasil.

Recebido 16/08/2018

Aprovado 23/08/2018

Received $08 / 16 / 2018$

Approved 08/23/2018

Recibido $16 / 08 / 2018$

Aceptado 23/08/2018

Como citar: Nascimento, L. G., \& Bandeira, M. M. B. (2018). Saúde penitenciária, promoção de saúde e redução de danos do encarceramento: Desafios para a prática do Psicólogo no sistema prisional. Psicologia: Ciência e Profissão, 38(n.spe.2), 102-116. https://doi.org/10.1590/1982-3703000212064

How to cite: Nascimento, L. G., \& Bandeira, M. M. B. (2018). Penitentiary health, health promotion and harm reduction of imprisonment: Challenges to the Psychologist's practice in the prison system. Psicologia: Ciência e Profissão, 38(n.spe.2), 102-116. https://doi.org/10.1590/1982-3703000212064

Cómo citar: Nascimento, L. G., \& Bandeira, M. M. B. (2018). Salud penitenciaria, promoción de salud y reducción de daños del encarcelamiento: Desafíos para la Práctica del Psicólogo en el sistema penitenciario. Psicologia: Ciência e Profissão, 38(n.spe.2), 102-116. https://doi.org/10.1590/1982-3703000212064 